УДК 547.314

\title{
КУМАРИНОВЫЕ ПРОИЗВОДНЫЕ КОРНЕЙ ANGELICA SACHOKIANA (KARJAG.) M.PIMEN. ET V.TIKHOMIROV
}

\author{
(C) Г.А. Иманлы, С.В. Серкеров" \\ Институт ботаники Национальной академии наук Азербайджана, \\ Бадамдарское шоссе, 40, Баку, AZ1073 (Азербайджан), \\ e-mail: s.serkerov@mail.ru
}

Работа посвящена исследованию биологически активных веществ - кумариновых производных Angelica sachokiana (Karjag.) M.Pimen. et V.Tikhomirov (Apiaceae Lindl.), собранных в фазу плодоношения. С этой целью использован метод колоночной хроматографии суммы экстрактивных веществ, полученных экстракцией ацетоном мелкоизмельченных воздушно-сухих корней растений. При элюировании хроматографической колонки гексаном, бензолом, хлороформом и их смесей в различных соотношениях в индивидуальном состоянии выделено четыре кристаллических вещества: $\mathrm{C}_{12} \mathrm{H}_{8} \mathrm{O}_{4}$, т. пл. $188-191^{\circ} \mathrm{C} ; \mathrm{C}_{12} \mathrm{H}_{8} \mathrm{O}_{4}$, т. пл. $145-146{ }^{\circ} \mathrm{C} ; \mathrm{C}_{13} \mathrm{H}_{10} \mathrm{O}_{5}$, т. пл. $117-119{ }^{\circ} \mathrm{C}$ и $\mathrm{C}_{21} \mathrm{H}_{22} \mathrm{O}_{7}$, т. пл. 136-137 ${ }^{\circ} \mathrm{C}$. На основании данных ИК-ЯМР ${ }^{1} \mathrm{H},{ }^{13} \mathrm{C},{ }^{13} \mathrm{C}$ Dept 135 спектров доказано, что они имеют строение, идентичное бергаптену, ксантотоксину, пимпинеллину, острутолу соответственно.

Ключевые слова: Angelica sachokiana, Apiaceae, экстракция, хроматография, элюация, спектроскопия, кумарины, фурокумарины, бергаптен, ксантотоксин, пимпинеллин, острутол, ИК-, ЯМР- спектры, химический сдвиг.

\section{введение}

Во флоре Азербайджана род Angelica представлен двумя видами: Angelica sachokiana (Karjag.) M.Pimen et V.Tikhomirov (=Xanthogalum sachokianum Karjag.) и A. purpurascens (Ave-Lall.) Gilli ( $X$. purpurascens Ave-Lall.) [1]. Согласно литературным данным из корней A. sachokiana, собранных в Ахтынском районе Республики Дагестан, выделены острутол, изопимпинеллин и $\beta$-ситостерин, а из плодов - умбеллипренин, бергаптен, биакангелицин и ксанталин [2].

Производные кумарина широко распространены в растительном мире, особенно среди представителей семейств сельдерейных, рутовых, бобовых. Кумарины также обнаружены в продуктах жизнедеятельности микроорганизмов и животных [3]. В настоящее время изучена биологическая активность некоторых индивидуальных производных кумарина, выделенных из различных видов семейства Apiaceae. Например, фотосенсибилизирующей активностью обладают псорален, бергаптен, ксантотоксин, императорин, изопимпинеллин. На основе этих фурокумаринов создан целый ряд высокоэффективных лекарственных препаратов: меладинин, бероксан, псорален, псоберан, метоксален и аммифурин, широко применяемые в медицинской практике при лечении витилиго [4-8].

Цель данной работы - выделение и установление структуры кумаринов из корней Angelica sachokiana.

\section{Материалы и методы}

Материалом для исследования служили воздушно-сухие, мелкоизмельченные корни Angelica Иманлы Гилал Аршад огль - диссертант, e-mail: s.serkerov@mail.ru

Серкеров Сираджеддин Вели огль - заслуженный деятель науки Азербайджана, главный научный сотрудник отдела растительных ресурсов, доктор химических наук, профессор, e-mail: s.serkerov@mail.ru sachokiana, собранные во время плодоношения в окрестностях села Кузун Гусарского района Азербайджанской Республики. Гербарные образцы определены 3.С. Алиевой и хранятся в коллекции гербария Института ботаники НАН Азербайджана. Экстракцию корней (330 г) проводили ацето-

\footnotetext{
* Автор, с которым следует вести переписку.
} 
ном трижды, продолжительность каждой экстракции - 72 ч. Получено 18,0 г суммы экстрактивных веществ (выход - 5,45 \% от массы сырья).

10,0 г суммы экстрактивных веществ подвергали хроматографическому разделению на колонке с нейтральной окисью алюминия (III-IV степени активности по Брокману). Элюирование проводили гексаном (10 фракций), смесью гексана с бензолом в соотношении $2: 1$ (15 фракций), смесью гексана и бензола $1: 1$ (25 фракций), смесью бензола с хлороформом $1: 1$ и хлороформом. Объем каждой фракции 100 мл.

Индивидуальность веществ определяли на пластинках Silufol UV 254. Температуру плавления кристаллических веществ определяли на столике Боэтиуса. ИК-спектры регистрировали на спектрофотометре «Specord» в вазелиновом масле. Спектры ЯМР ${ }^{1} \mathrm{H}$ и ${ }^{13} \mathrm{C}$ снимали на спектрометре Bruker 300 с резонансной частотой 300 МГц для ${ }^{1} \mathrm{H}$ и 75 МГц для ядер ${ }^{13} \mathrm{C}$. Растворитель - диметилсульфооксид (DMSO). Химические сдвиги даны по $\delta$-шкале. Внутренний стандарт - ТМС. Условные обозначения: с - синглет, д - дублет, т - триплет, к - квартет, ск - секстет, м - мультиплет.

\section{Результаты и обсуждение}

Из фракций 9-10, полученных при элюировании смесью гексана и бензола $(2: 1)$, выделили кристаллическое вещество 1 состава $\mathrm{C}_{12} \mathrm{H}_{8} \mathrm{O}_{4}$ с т.пл. $188-191{ }^{\circ} \mathrm{C}$. ИК-спектр вещества имеет полосы поглощения $\delta$-лактонного цикла $\left(1732 \mathrm{~cm}^{-1}\right)$ и ароматической системы $\left(1621,1583 \mathrm{~cm}^{-1}\right)$.

В ЯМР-спектре исследуемого соединения проявляется синглет с площадью трех протонных единиц при 4,22 м.д., принадлежащий метоксильной группе. В области слабого магнитного поля спектра обнаружены однопротонные сигналы при 6,30 (д., 9,65 Гц, Н-4), 8,20 (д., 9,65 Гц, Н-3), 7,30 (с., Н-8), 7,40 (д., 2,00 Гц, Н-3') и 8,00 м.д. (д., 2,00 Гц, Н-2'), которые указывают на принадлежность вещества к группе фурокумаринов псораленовой группы [9]. На основании изучения данных ${ }^{1} \mathrm{H}$ ЯМР- и ИК-спектров вещества и сопоставления их с литературными данными фурокумаринов псораленовой группы установлено, что исследуемому соединению соответствует строение бергаптена $[3,6]$.

Фракции $12-14$, полученные элюированием смесью гексана и бензола $(2: 1)$, содержали кристаллическое вещество 2 состава $\mathrm{C}_{12} \mathrm{H}_{8} \mathrm{O}_{4}$ с т.пл. $145-146^{\circ} \mathrm{C}$. В области характеристических частот ИК-спектра вещества найдены полосы поглощения $\delta$-лактонного цикла $\left(1730 \mathrm{~cm}^{-1}\right)$ и двойных связей ароматической системы $\left(1630,1600,1560 \mathrm{~cm}^{-1}\right)$.

Обнаруживаемый ${ }^{1} \mathrm{H}$ ЯМР-спектром трехпротонный синглет при 4,25 м.д. свидетельствует о присутствии в молекуле исследуемого соединения метоксильной группы. Однопротонные сигналы в слабом магнитном поле спектра при 6,32 (д., 9,65 Гц, 1Н, Н-4), 7,73 (д., 9,65 Гц, 1Н, Н-3), 7,32 (с., 1Н, Н-5), 6,80 (д., 2,00 Гц, Н-3'), 7,60 м.д. (Д., 2,00 Гц, Н-2') принадлежат протонам ароматической системы. Анализ полученных спектральных данных позволяет сделать вывод, что исследуемое соединение 2 имеет строение, идентичное ксантотоксину [10].

При элюировании хроматографической колонки смесью гексана и бензола $(1: 1)$ из фракции 25-28 выделили вещество 3 состава $\mathrm{C}_{13} \mathrm{H}_{10} \mathrm{O}_{5}$, с т.пл. $117-119^{\circ} \mathrm{C}$. В ИК-спектре имеются полосы поглощения при 1740 и $1628,1580,1545 \mathrm{~cm}^{-1}$, позволяющие отнести исследуемое вещество 3 к производным кумарина [10].

В ${ }^{1} \mathrm{H}$ ЯМР-спектре вещества 3 обнаружены сигналы двух метоксильных групп 3,95 (с., 3Н, $\mathrm{CH}_{3} \mathrm{O}-$ ), 4.10 м.д. (с., 3Н, $\left.\mathrm{CH}_{3} \mathrm{O}-\right)$, протонов ароматической системы: Н-4 (6,45 м.д, д., 11 Гц, 1Н), Н-3 (8,15 м.д, д., 11 Гц, 3Н) и протонов фуранового цикла: 7,25 (д., 2,3 Гц, 1Н), 8,15 м.д, (д., 2,3 Гц, 1Н).

Данные ${ }^{1} \mathrm{H}$ ЯМР-спектра исследуемого вещества 3 указывают на принадлежность последнего к группе фурокумаринов ангелициновой группы. На основании сопоставления полученных данных с литературными [11] вещество 3 идентифицировано как пимпинеллин.

Вещество 4, выделенное из 38-43 фракций элюированием смесью бензола с хлороформом (1:1), имеет состав $\mathrm{C}_{21} \mathrm{H}_{22} \mathrm{O}_{7}$ и т. пл. $137-138^{\circ} \mathrm{C}$ (из смеси хлороформа с гексаном). В области характеристических частот ИК-спектра вещество 4 имеет полосы гидроксильной группы $\left(3487 \mathrm{~cm}^{-1}\right)$, карбонильных групп лактонного цикла и $\alpha, \beta$-ненасыщенной сложноэфирной группы $\left(1716 \mathrm{~cm}^{-1}\right)$, двойных связей ароматической системы и сложно-эфирной группы $\left(1646,1625,1605,1580,1546\right.$ см$\left.^{-1}\right)$.

Характер сложно-эфирной группы в молекуле вещества 4 определен омылением его щелочью. При этом получены два вещества: ангеликовая кислота с т.пл. $45^{\circ} \mathrm{C}$ и вещество $4 \mathbf{a}$, состава $\mathrm{C}_{16} \mathrm{H}_{16} \mathrm{O}_{6}$ с т.пл. $136-138^{\circ} \mathrm{C}$ (из водного этанола, см. схему ниже).

В ИК-спектре вещества 4а найдены полосы гидроксильных групп (3400 $\left.\mathrm{cm}^{-1}\right)$, СО- группы лактонного цикла $\left(1720 \mathrm{~cm}^{-1}\right)$ и ароматической системы $\left(1620,1610\right.$ и плечо $\left.1584,1555 \mathrm{~cm}^{-1}\right)$. 
<smiles>CC=C(C)C(=O)OC(O)c1cc2c(OCC(O)C(C)(C)O)c3ccc(=O)oc3cc2o1</smiles>

(4) (4a)

${ }^{1}$ Н ЯМР-спектр омыленного
продукта (вещество 4а)

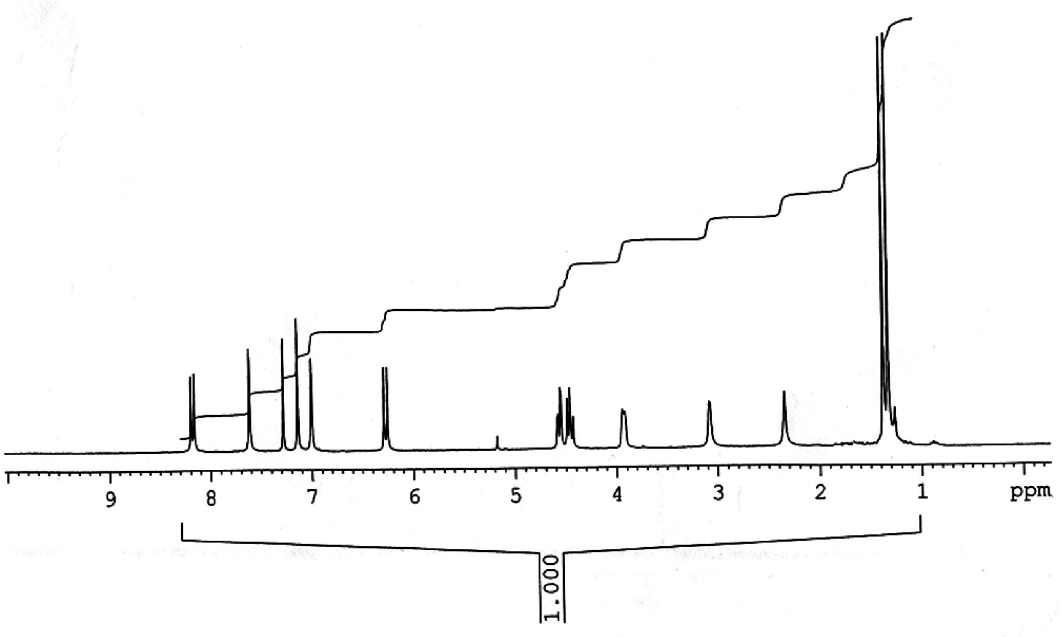

${ }^{1}$ Н ЯМР-спектр омыленного продукта (4а) (рис.) обнаруживает синглеты двух метильных групп (1,30 и 1,40 м.д, 3Н каждый), синглеты протонов двух гидроксильных групп (2,35 и 3,05 м.д, 1Н каждый), два триплета $\mathrm{CH}_{2}$-группы (4,45 и 4,55 м.д, каждый) и дублет, принадлежащий гем-гидроксильному протону (3,90 м.д, 1Н). Сигналы, находящиеся в слабом магнитном поле спектра (д., 630, 9,65 Гц, 1Н, Н-4; 8,20, д., 9,65 Гц, 1Н, Н-3; 7,30, с., 1Н, Н-8; 7,00, д., 2,3 Гц, Н-3' и 7,60 м.д, д., 2,3 Гц, Н-2'), отнесены к фурокумариновой части исследуемого соединения.

В ${ }^{13} \mathrm{C}$ ЯМР-спектре омыленного продукта (4a), снятом с полным подавлением спин-спинового взаимодействия с протонами, проявляются 16 синглетных сигналов, которые указывают на наличие в молекуле 16 атомов углерода $(25,0 ; 27,0 ; 30,0 ; 71,0 ; 74,0 ; 94,0 ; 99,0 ; 104,0 ; 108,0 ; 111,5 ; 112,0 ; 119,0 ; 133,0 ; 139,0$; 145,$0 ; 161,0$ м.д). Из них в ${ }^{13} \mathrm{C}$ ЯMP Dept 135 спектре проявляются только девять сигналов, принадлежащих протонированным атомам углерода. Семь сигналов, имеющихся в спектре ${ }^{13} \mathrm{C}$ ЯМР, однако не обнаруженные в ${ }^{13}$ C ЯMP Dept 135 спектре, относятся к семи непротонированным атомам углерода молекулы.

На основании изучения продуктов химического превращения и спектральных (ИК-, ЯМР ${ }^{1} \mathrm{H},{ }^{13} \mathrm{C}$ Dept 135) данных установлено, что соединение 4a, полученное при омылении исходного вещества, имеет строение, идентичное гидрату оксипейцеданина, а исходное вещество 4, выделенное из корней Angelica sachokiana, представляет собой острутол - эфир ангеликовой кислоты и гидрата оксипейцеданина.

\section{Выводы}

1. Из ацетонового извлечения корней Angelica sachokiana (Karjag.) M.Pimen. et V.Tikhomirov методом колоночной хроматографии на окиси алюминия выделены четыре вещества кумариновой природы: $\mathrm{C}_{12} \mathrm{H}_{8} \mathrm{O}_{4}$, т.пл. $188-191{ }^{\circ} \mathrm{C}(\mathbf{1}), \mathrm{C}_{12} \mathrm{H}_{8} \mathrm{O}_{4}$, т. пл. $145-146{ }^{\circ} \mathrm{C}(\mathbf{2}), \mathrm{C}_{13} \mathrm{H}_{10} \mathrm{O}_{5}$, т. пл. $117-119{ }^{\circ} \mathrm{C}(\mathbf{3})$, и $\mathrm{C}_{21} \mathrm{H}_{22} \mathrm{O}_{7}$, т. пл. $136-137^{\circ} \mathrm{C}(4)$.

2. На основании химических и спектральных (ИК-, ${ }^{1} \mathrm{H},{ }^{13} \mathrm{C},{ }^{13} \mathrm{C}$ Dept 135 ЯMP-) данных установлено, что они имеет строение, идентичное бергаптену (1), ксантотоксину (2), пимпинеллину (3) и острутолу (4).

3. Ксантотоксин и пимпинеллин из A. sachokiana выделены впервые. 


\section{Список литературы:}

1. Czerepanov S.K. Vascular plants of Russia and adjacent states (The former USSR). Cambridge University Press. 1995. $516 \mathrm{p}$.

2. Флора Азербайджана. 1955. Т. 6. С. 274-276.

3. Керимов С.Ш. Кумарины Xanthogalum sachokianum // Химия природных соединений. 1986. №3. С. 371-372.

4. Кузнецова Г.А. Природные кумарины и фурокумарины. Л., 1967. 248 с.

5. Султанов М.Б. Псоберан - новый препарат для лечения витилиго и алопецин // Химико-фармацевтический журнал. 1981. №2. С. 108-110.

6. Кабилов Н.М. Сравнительное фотосенсибилизирующие действие келлина, меладинина и экстракта псоралеа Костянковой // Фармакология и токсикология. 1962. Т. 25, №6. С. 733-735.

7. Заградничек О. Лечение больных витилиго экстрактами Ammi majus // Вести дерматологии и венерологии. 1961. №5. C. 43-52.

8. Абышев А.З., Агаев Э.М., Керимов Ю.Б. Химия и фармакология природных кумаринов. Баку, 2003. 112 с.

9. Курбанова Ф.Г., Серкеров С.В. Новый метоксифурокумарин псораленовой группы из плодов Heracleum transcaucasicum // Химия природных соединений. 2012. №3. С. 340-341.

10. Серкеров С.В., Алескерова А.Н. Инфракрасные спектры и строение сесквитерпеновых лактонов и кумаринов. Баку, 2006. 223 с.

11. Курбанова Ф.Г. Кумарины зрелых плодов Heracleum transcaucasicum Manden. ex Grossh и цветочных зонтиков Sseseli transcaucasicum (Schischk.) M.Pimen. et Sdobn. // Новые достижения в химии и химической технологии растительного сырья : матер. 5 Всерос. конф. с междунар. участием. Барнаул, 2012. С. 282-284.

Поступило в редакиию 31 августа 2014 г.

После переработки 21 декабря 2015 г.

\section{Imanly G.A., Serkerov S.V. ${ }^{*}$ COUMARIN DERIVATIVES OF RESIN OF ROOTS OF THE ANGELICA SACHOKIANA (KARJAG.) M.PIMEN. ET V.TIKHOMIROV \\ Institute of Botany of the National Academy of Sciences of Azerbaijan, Badamdarskoe shosse, 40, Baku, AZ1073 \\ (Azerbaijan),e-mail: s.serkerov@mail.ru}

From the roots of Angelica sachokiana (Karjag.) M.Pimen. et V.Tikhomirov (Apiaceae Lindl.), collected in the phase of fruiting isolated four substances: $\mathrm{C}_{12} \mathrm{H}_{8} \mathrm{O}_{4}$, m.p. $188-191{ }^{\circ} \mathrm{C}$ (I, IR: 1732, 1621, $1583 \mathrm{~cm}^{-1}$; ${ }^{1} \mathrm{H}$ NMR: 6,30, d., J=9,65 Hz, H-4; 8,20, d., J=9,65 Hz, H-3, 7,30, s., H-8; 7,40 d., J=2,00 Hz, H-3'; 8,00, d., J=2,00 Hz, H-2'); $\mathrm{C}_{12} \mathrm{H}_{8} \mathrm{O}_{4}$, m.p. $145-146^{\circ} \mathrm{C}$ (II, IR: 1730, 1630, 1600, $1560 \mathrm{~cm}^{-1}$; ${ }^{1} \mathrm{H}$ NMR: 6,32, d., J=9,65 Hz, H-4; 7,73, d., J=9,65 Hz, H-3; 7,32, s., H-5, 6,80, d., J=2,00 Hz, H3'; 7,60, d., J=2,00 Hz, H-2'); $\mathrm{C}_{13} \mathrm{H}_{10} \mathrm{O}_{5}$, m.p. $117-119^{\circ} \mathrm{C}$ (III, IR: 1740, 1628, 1580, $1545 \mathrm{~cm}^{-1}$; ${ }^{1} \mathrm{H}$ NMR: 3,95, c., $\mathrm{CH}_{3} \mathrm{O}-$; 4,10, c., $\mathrm{CH}_{3}-\mathrm{O}-;$; 6,45, d., J=11,00 Hz, H-4; 8,15, d., J=11,00 Hz, H-3; 7,25, d., J=2,30 Hz, H-3'; 8, 15 ppm, d., J=2,30 Hz, H$\left.2^{\prime}\right)$ and $\mathrm{C}_{21} \mathrm{H}_{22} \mathrm{O}_{7}$, m.p. $136-137^{\circ} \mathrm{C}$ (IV, IR: $\left.3487,1716,1646,1625,1605,1580,1546 \mathrm{~cm}^{-1}\right)$. Saponification with an alkali substance IV formed angelic acid oxypeucedanine hydrate that are identified on the basis of IR, ${ }^{1} \mathrm{H},{ }^{13} \mathrm{C},{ }^{13} \mathrm{C}$ Dept $135 \mathrm{NMR}$ spectra. On the basis of chemical and spectral data the substance I, II, III and IV identified as bergaptene, xanthotoxin, pimpinellin and ostruthol, respectively.

Keywords: Angelica sachokiana, Apiaceae, extraction, chromatography, elution, Spectroscopy, coumarin, furokumariny, bergapten, xanthotoxin, pimpinella, ostrutol, IR, NMR spectra, chemical shift.

\section{References}

1. Czerepanov S.K. Vascular plants of Russia and adjacent states (The former USSR). Cambridge University Press. 1995. $516 \mathrm{p}$.

2. Flora Azerbaidzhana. [Flora of Azerbaijan]. 1955, vol. 6, pp. 274-276. (in Russ.).

3. Kerimov S.Sh. Khimiia prirodnykh soedinenii, 1986, no. 3, pp. 371-372. (in Russ.).

4. Kuznetsova G.A. Prirodnye kumariny i furokumariny. [Natural coumarins and furokumariny]. Leningrad, 1967, 248 p. (in Russ.).

5. Sultanov M.B. Khimiko-farmatsevticheskii zhurnal, 1981, no. 2, pp. 108-110. (in Russ.).

6. Kabilov N.M. Farmakologiia i toksikologiia, 1962, vol. 25, no. 6, pp. 733-735. (in Russ.).

7. Zagradnichek O. Vesti dermatologii $i$ venerologii, 1961, no. 5, pp. 43-52. (in Russ.).

8. Abyshev A.Z., Agaev E.M., Kerimov Iu.B. Khimiia i farmakologiia prirodnykh kumarinov. [Chemistry and Pharmacology of natural coumarins]. Baku, 2003, 112 p. (in Russ.).

9. Kurbanova F.G., Serkerov S.V. Khimiia prirodnykh soedinenii, 2012, no. 3, pp. 340-341. (in Russ.).

10. Serkerov S.V., Aleskerova A.N. Infrakrasnye spektry i stroenie seskviterpenovykh laktonov $i$ kumarinov. [Infrared spectra and structure of the sesquiterpene lactones and coumarins]. Baku, 2006, 223 p. (in Russ.).

11. Kurbanova F.G. Novye dostizheniia v khimii i khimicheskoi tekhnologii rastitel'nogo syr'ia : mater. 5 Vseros. konf. $s$ mezhdunar. uchastiem. [Advances in chemistry and chemical technology of vegetable raw materials: materials 5 AllRussian conference with international participation]. Barnaul, 2012, pp. 282-284. (in Russ.).

\footnotetext{
* Corresponding author.
} 